Research Article

\title{
Simultaneous Detection of Ascorbic Acid, Dopamine, and Uric Acid Using a Novel Electrochemical Sensor Based on Palladium Nanoparticles/Reduced Graphene Oxide Nanocomposite
}

\author{
Yuyun Wei, ${ }^{1}$ Yangyang Liu, ${ }^{1}$ Zhifang Xu $\mathbb{D}^{1},{ }^{1}$ Shenjun Wang, ${ }^{1}$ Bo Chen, ${ }^{1}$ Di Zhang $\mathbb{D},{ }^{2}$ \\ and Yuxin Fang $\mathbb{1}^{1}$ \\ ${ }^{1}$ Research Center of Experimental Acupuncture Science, College of Acumox and Tuina, \\ Tianjin University of Traditional Chinese Medicine, Tianjin 301617, China \\ ${ }^{2}$ College of Pharmaceutical Engineering of Traditional Chinese Medicine, Tianjin University of Traditional Chinese Medicine, \\ Tianjin 301617, China
}

Correspondence should be addressed to Di Zhang; 43987073@qq.com and Yuxin Fang; meng99_2006@126.com

Received 9 June 2020; Revised 19 November 2020; Accepted 30 November 2020; Published 17 December 2020

Academic Editor: Anastasios S. Economou

Copyright (c) 2020 Yuyun Wei et al. This is an open access article distributed under the Creative Commons Attribution License, which permits unrestricted use, distribution, and reproduction in any medium, provided the original work is properly cited.

\begin{abstract}
A fresh strategy based on two-step electrochemical reduction for the fabrication of palladium nanoparticles/reduced oxide nanocomposite-modified glass carbon electrode (PdNPs/rGO/GCE) was established in this study. Field emission scanning electron microscopy (FESEM) images showed that spherical PdNPs were evenly distributed on the surface of rGO-modified electrode (rGO/ GCE), and the introduction of PdNPs has no effect on the morphology of rGO. Electrochemical impedance spectroscopy (EIS) studies revealed that the conductivity of PdNPs/rGO/GCE was higher than that of rGO/GCE and bare GCE. The electrochemical performances of PdNPs/rGO/GCE sensor were investigated by cyclic voltammetry (CV), differential pulse voltammetry (DPV), and chronoamperometry using ascorbic acid (AA), dopamine (DA), and uric acid (UA) as analytes. At the optimized conditions, wide linear ranges of $0.5-3.5 \mathrm{mM}\left(R^{2}=0.99\right), 3-15 \mu \mathrm{M}\left(R^{2}=0.99\right)$ and $15-42 \mu \mathrm{M}\left(R^{2}=0.99\right)$, and $0.3-1.4 \mathrm{mM}\left(R^{2}=0.99\right)$ towards AA, DA, and UA in ternary mixture were observed, respectively. In addition to superior anti-interference capability, fast response ( $\leq 5 \mathrm{~s})$, excellent reproducibility, and good long-term stability were also given by this sensor. These results suggested that PdNPs/rGO/GCE is promising for the simultaneous detection of AA, DA, and UA in practical application.
\end{abstract}

\section{Introduction}

Noble metal nanoparticles, a kind of metal nanomaterial, are often used as enhancement elements in electrochemical sensors due to their excellent electrocatalytic activity, rapid electron transfer ability, strong stability, and good biocompatibility [1-4]. Several noble metal nanoparticles, such as gold, silver, and platinum, are not suitable for commercialization due to their high cost and low availability. In contrast, palladium nanoparticles (PdNPs), an emerging noble metal nanoparticle, have been favored by researchers in recent years because of their higher abundance, lower cost, and well-resisted toxic intermediates [5-7]. However, the aggregation of PdNPs needs to be well addressed before mass application.

Researches showed that carbon nanomaterials including carbon nanotubes, carbon dots, and graphene are beneficial to the dispersion of nanoparticles due to their unique structure, large specific surface area, and high catalytic activity $[3,8]$. Among them, carbon dots are more suitable for fluorescent sensors due to their unique optical properties, while carbon nanotubes are prone to serious entanglement due to their inherent strong van der Waals interaction that requires additional dispersants. Neither of them can meet people's demand for low-cost and high-performance biosensing platforms [9]. In practical application, high-quality 
graphene (reduced graphene oxide, rGO) is often prepared by electrochemical reduction of graphene oxide (GO), which is simple and cost-effective. The residual oxygen functional groups and the recovery of the conjugated network make rGO possess hydrophilicity and high conductivity [10-12]. Hence, $r G O$ is considered to be the most promising carbon nanomaterials for dispersing PdNPs [13-15].

As biological molecules of great significance to human health, the abnormal changes in ascorbic acid (AA), dopamine (DA), and uric acid (UA) in human body can bring serious threats including cancer, Parkinson's disease, and leukemia [16-18]. Therefore, the development of a rapid and effective electrochemical senor for simultaneous detection of these three substances is in urgent need.

Herein, PdNPs/rGO/GCE was fabricated by facile twostep electrodeposition to detect AA, DA, and UA simultaneously. Although the preparation of $\mathrm{PdNPs} / \mathrm{rGO}$ nanocomposites has been reported [19-21], most of them are prepared through a multistep complex process, which not only involves chemicals that may cause health and environmental risks but also contains long-time consumption. In addition to good catalytic activity and rapid response $(\leq 5 \mathrm{~s})$, the sensor prepared in this work also exhibited high reproducibility and stability.

\section{Experimental}

2.1. Reagents. AA (99.7\%) was obtained from Lianxing Biotechnology (Tianjin); dopamine hydrochloride (DA, 98\%) was purchased from Sigma-Aldrich (Shanghai); UA $(59.0 \%-60.0 \%)$ and palladium chloride were provided by Ron Chemical Reagent Company (Tianjin); potassium chloride $(\mathrm{KCl}, 99.0 \%)$, potassium ferricyanide, sodium dihydrogen phosphate $\left(\mathrm{NaH}_{2} \mathrm{PO}_{4}, 99.0 \%\right)$, and disodium hydrogen phosphate $\left(\mathrm{Na}_{2} \mathrm{HPO}_{4}, \geq 99.0 \%\right)$ were obtained from Chemical Reagent Supply and Marketing company (Tianjin); GO (99.8\%) was provided by Xianfeng Nano Materials Technology (Nanjing). Phosphate buffer (PB) solution with different $\mathrm{pH}$ values was prepared with the mixed solution of $\mathrm{NaH}_{2} \mathrm{PO}_{4}$ and $\mathrm{Na}_{2} \mathrm{HPO}_{4}$ in a certain proportion. Ultrapure water was used throughout all measurements.

2.2. Apparatus. High-resolution transmission electron microscopy (HRTEM) and energy-dispersive spectroscopy (EDS) were finished on a FEI-Talos-F200X equipped with an energy-dispersive spectrometer analyzer. Field emission scanning electron microscope (FESEM) images were obtained with a Nova NanoSEM 430 (FEI, USA). Cyclic voltammetry (CV), differential pulse voltammetry (DPV), and chronoamperometry measurements were performed using a AMETEK PARSTAT 4000 electrochemical workstation (AMETEK Commercial Enterprise (Shanghai) Co., Ltd. Beijing Branch.) with a three-electrode system, while PdNPs/rGO/GCE, platinum electrode, and saturated calomel electrode (SCE) were used as a working electrode, counterelectrode, and reference electrode, respectively.
KQ-600KDE high-power CNC ultrasonic cleaner was purchased from Ultrasonic Instrument Co., Ltd (Kunshan). Magnetic stirrer was provided by Ronghua Instrument Manufacturing Co., Ltd (Changzhou).

2.3. Fabrication of $P d N P s / r G O / G C E$. Before modification, the bare GCE was successively polished with $1 \mu \mathrm{m}$, $0.3 \mu \mathrm{m}$, and $0.05 \mu \mathrm{m} \mathrm{Al}_{2} \mathrm{O}_{3}$ slurry and then washed ultrasonically in ultrapure water and ethanol to get a clean surface.

$40 \mathrm{mg}$ of GO powder was completely dissolved in $40 \mathrm{~mL}$ of ultrapure water under sonification for $60 \mathrm{~min}$ to obtain GO solution. The rGO/GCE was fabricated in GO solution by using the $\mathrm{CV}$ method between +1 and $-1.5 \mathrm{~V}$ with a scan rate of $50 \mathrm{mV} \cdot \mathrm{s}^{-1}$ for 19 cycles; after that, the modified electrode was washed with ultrapure water and dried at room temperature.

Then, $0.0035 \mathrm{~g}$ palladium chloride was directly added in $20 \mathrm{~mL}$ of ultrapure water to obtain $1 \mathrm{mM}$ palladium chloride solution, and $6 \mu \mathrm{L}$ of the solution was cast on the surface of rGO/GCE. After the solution was totally dried, the electrode was immersed in $0.1 \mathrm{M} \mathrm{KCl}$ solution and then treated by applying $-0.7 \mathrm{~V}$ for $1800 \mathrm{~s}$ for electrodeposition of PdNPs, and then, PdNPs/rGO/GCE was fabricated. Then, the obtained sensor was washed with ultrapure water and dried for later use (Scheme 1).

2.4. Electrochemical Measurements. The EIS measurements were performed from $10^{-2}$ to $10^{5} \mathrm{~Hz}$ with an amplitude of $+5 \mathrm{~V}$ and a bias voltage of $+0.24 \mathrm{~V}$. DPV curves were obtained from $-1.5 \mathrm{~V}$ to $+1.5 \mathrm{~V}$ at an amplitude of $50 \mathrm{mV}$ and a pulse width of $0.2 \mathrm{~s}$. In addition, since $\mathrm{CV}$ technology and chronoamperometry have been used many times in this paper and the parameter settings of the same method were different, the corresponding parameter settings were introduced in the related experiments.

\section{Results and Discussion}

3.1. Characterization of $P d N P s / r G O$ Nanocomposite. The results of FESEM and HRTEM of PdNPs/rGO nanocomposite are demonstrated in Figures $1(\mathrm{a})-1(\mathrm{c})$. It is evident that the synthesized rGO has a typical folded structure $[22,23]$; furthermore, the PdNPs synthesized on the surface of the rGO were spherical and highly uniform in size, which not only has no effect on the morphology of the rGO but also helps to increase the surface area of the electrode (Figures 1(a) and 1(b)). From the HRTEM image (Figure 1(c)), it was obtained that the PdNPs with an average diameter less than $50 \mathrm{~nm}$ [24] were uniformly dispersed on the surface of rGO, which coincides with the result of Figure 1(b) and literature [25]. EDS characterization results (Figure S1) further confirm that the PdNPs/rGO nanocomposite was successfully prepared.

$\mathrm{CV}$ and EIS were used to examine the electrochemical behavior of $\mathrm{PdNPs} / \mathrm{rGO} / \mathrm{GCE}$ in $20 \mathrm{mM}$ potassium ferricyanide solution containing $0.1 \mathrm{M} \mathrm{KCl}$. CV curves were obtained from $-0.6 \mathrm{~V}$ to $+0.8 \mathrm{~V}$ with scan rate of $50 \mathrm{mV} \mathrm{s}^{-1}$ 


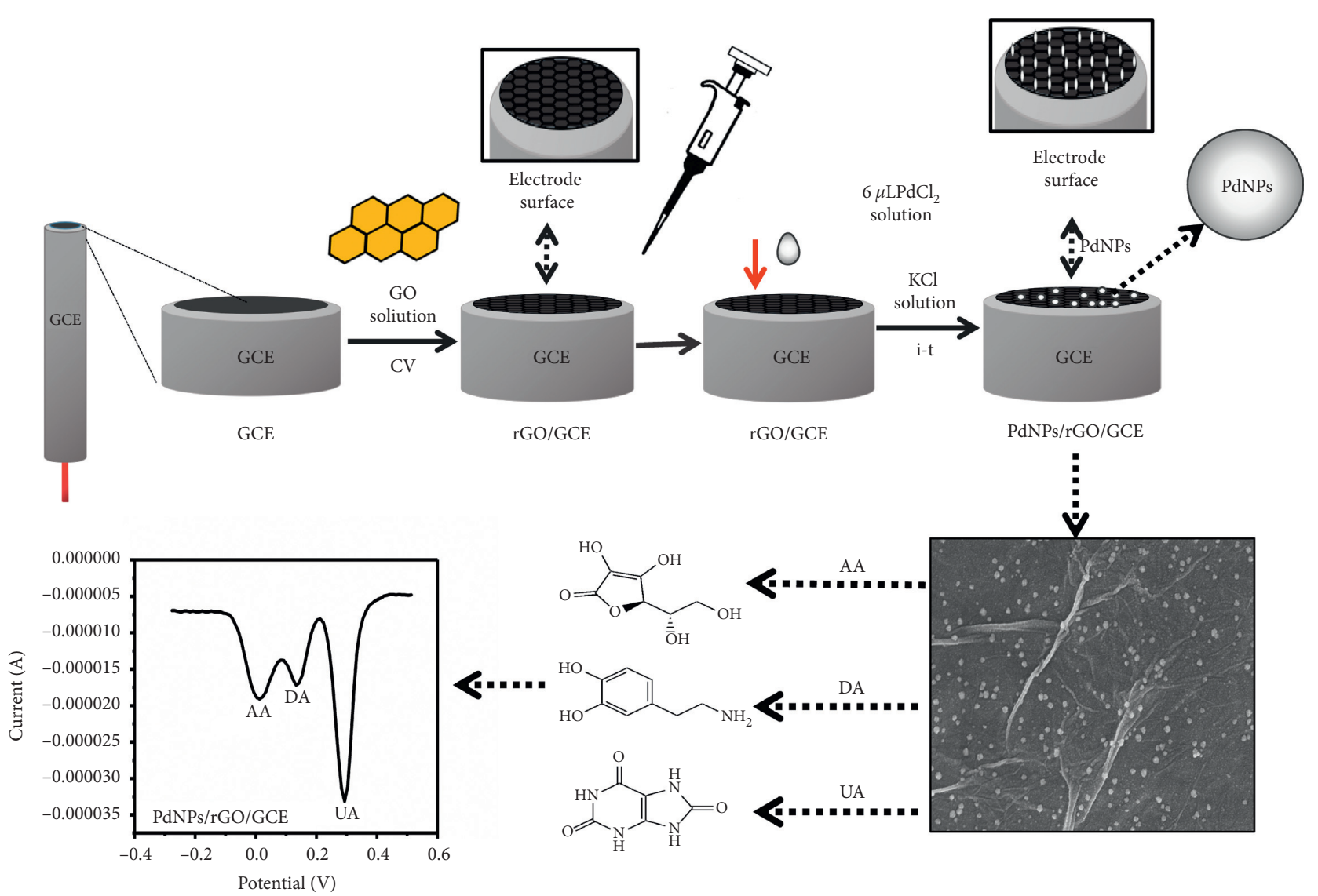

Scheme 1: Steps for fabrication of PdNPs/rGO/GCE.

for 3 weeks. The active area of different electrodes was calculated by following Randle Sevick's equation [26]:

$$
A=\frac{I_{p a}}{\left(2.69 \times 10^{5}\right)} C n^{3 / 2} v^{1 / 2} D^{1 / 2},
$$

where $I_{p a}$ is the anode peak current of different electrodes in $\mathrm{CV}$ experiments (Figure S2), $C$ is the concentration of potassium ferricyanide solution (i.e., $20 \mathrm{mM}$ ), $n$ is the number of electrons, $v$ is the scan rate, and $D$ is the diffusion coefficient. The active surface ratio of bare GCE, rGO/GCE, and PdNPs/rGO/GCE was calculated as $1: 1.2: 1.3$, suggesting that the modification of $\mathrm{rGO}$ and $\mathrm{PdNPs} / \mathrm{rGO}$ nanocomposite on the surface of bare GCE helps to increase the active area of the electrode that can improve the catalytic ability of bare GCE.

From Figure 1(d), the results of EIS were given in the form of Nyquist plot, in which the diameter of highfrequency semicircle part represents the resistance of charge transfer (Rct) of the electrode surface [27] and low-frequency linear part represents the diffusion process [28]. Randle's circuit (inset of Figure 1(d)) was chosen to fit the impedance data obtained. The semicircle diameter at PdNPs/rGO/GCE and rGO/GCE was much smaller than that of bare GCE $(200 \Omega, 400 \Omega$, and $3000 \Omega$, respectively), indicating that the modification of rGO and PdNPs/rGO nanocomposites can all help to promote the electron transfer of bare GCE. And the enhancement effect of $\mathrm{PdNPs} / \mathrm{rGO} / \mathrm{GCE}$ was greater than that of $\mathrm{rGO} / \mathrm{GCE}$, which can be attributed to the increase in the contact area between the electrode surface and the analytes after electrodeposition of PdNPs. The result of EIS was consistent with $\mathrm{CV}$ characterization (Figure S2).

3.2. Effect of $p H$. The effect of $\mathrm{pH}$ of the supporting electrolyte (i.e., $0.1 \mathrm{MPB}$ ) on the electrochemical behavior of AA, DA, and UA was studied by DPV. As shown in Figure 2(a), with the $\mathrm{pH}$ values varied from 6.4 to 7.6 , the peak current of AA and UA reaches the maximum at $\mathrm{pH} 7.2$ (blue line), while DA reaches at $\mathrm{pH} 6.8$ (red line). To clearly observe the influence of $\mathrm{pH}$ values on the peak potential of these three substances, the method of translation was used to 


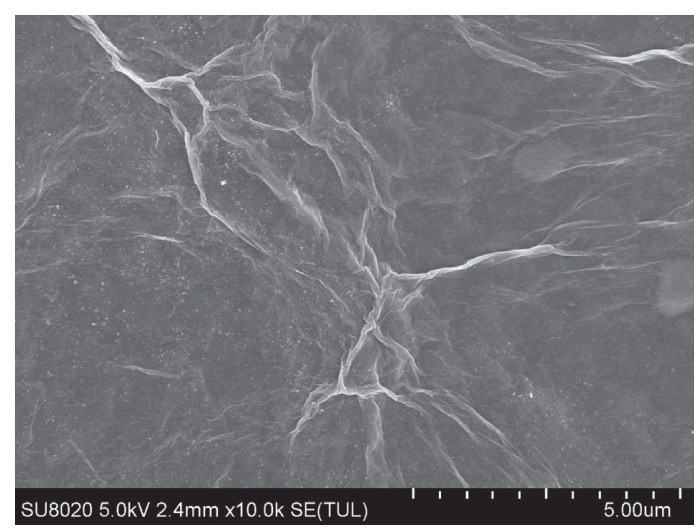

(a)

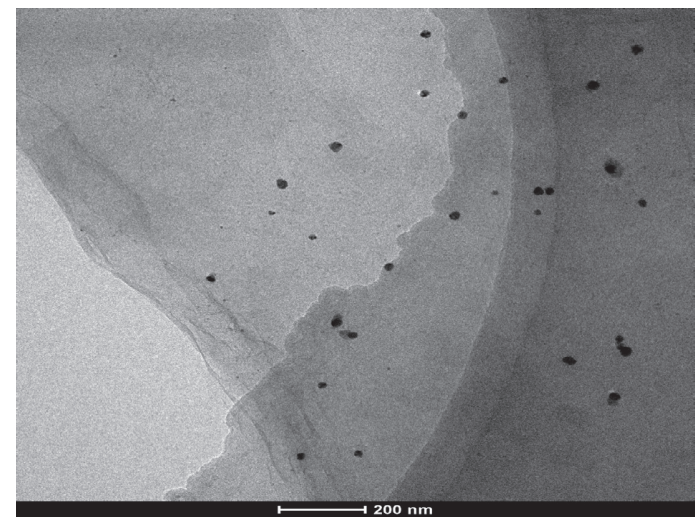

(c)

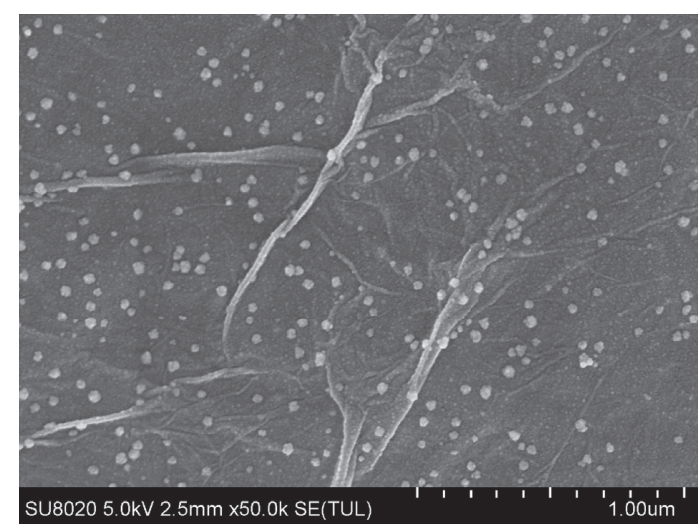

(b)

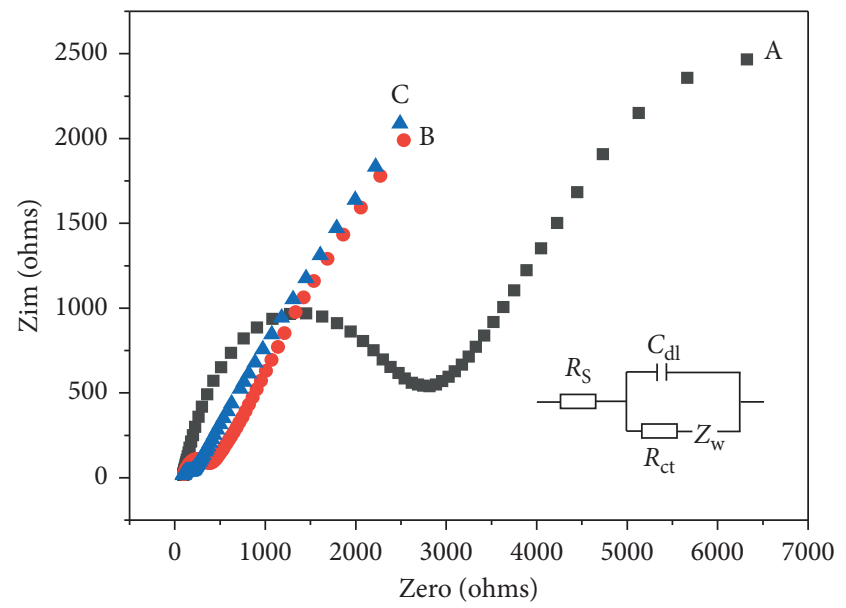

(d)

FIGURE 1: (a) FESEM characterization of rGO; (b) FESEM characterization of PdNPs/rGO nanocomposites; (c) HRETM characterization of PdNPs/rGO nanocomposites; (d) EIS characterization of bare GCE (A), rGO/GCE (B), and PdNPs/rGO/GCE (C) in 20 mM potassium ferricyanide solution containing $0.1 \mathrm{M} \mathrm{KCl}$.

separate the four curves. As can be seen from Figure 2(b), the peak potentials of AA, DA, and UA shift negatively with increasing $\mathrm{pH}$ values, and the peak potential differences of AA-DA and DA-UA reach the maximum at $\mathrm{pH} 7.2$, suggesting that protons were involved in the oxidation reaction of AA, DA, and UA [29].

Based on above, $0.1 \mathrm{M} \mathrm{PB}$ with $\mathrm{pH}$ value of 7.2 was selected as the measurement medium in subsequent experiments.

3.3. Effect of Scan Rate. The influence of scan rate on the redox behavior of $1 \mathrm{mM} \mathrm{AA}, 80 \mu \mathrm{M} \mathrm{DA}$, and $500 \mu \mathrm{M}$ UA was studied in $0.1 \mathrm{M} \mathrm{PB}$ using $\mathrm{CV}$ from $-0.6 \mathrm{~V}$ to $+0.6 \mathrm{~V}$ for 3 weeks (Figure 3). It can be seen that the oxidation peak currents of AA, DA, and UA and the reduction peak current of DA were proportional to increasing scan rate from 50 $\mathrm{mv} \cdot \mathrm{s}^{-1}$ to $250 \mathrm{mv} \cdot \mathrm{s}^{-1}$, and the linear regression equations were summarized as follows:

$$
\begin{aligned}
& \text { AA: } I_{p a}=10.64+0.039 v\left(R^{2}=0.99\right) ; \\
& \text { DA: } I_{p a}=4.397+0.036 v\left(R^{2}=0.99\right), \\
& I_{p c}=-1.969-0.024 v\left(R^{2}=0.99\right) ; \\
& \text { UA: } I_{p a}=5.124+0.028 v\left(R^{2}=0.99\right),
\end{aligned}
$$

where $v$ is the scan rate and $R^{2}$ is the correlation coefficient. The results proved that the electrochemical reaction of AA, DA, and UA was adsorption-controlled process [30, 31].

In addition, there was no obvious reduction peak in AA and UA, which may be related to the selection of detection concentration.

3.4. Electrochemical Detection of $A A, D A$, and UA. The analytical performances of PdNPs/rGO/GCE for AA, DA, and $\mathrm{UA}$ in $0.1 \mathrm{MPB}(\mathrm{pH} 7.2)$ were examined by DPV at the optimized conditions. 


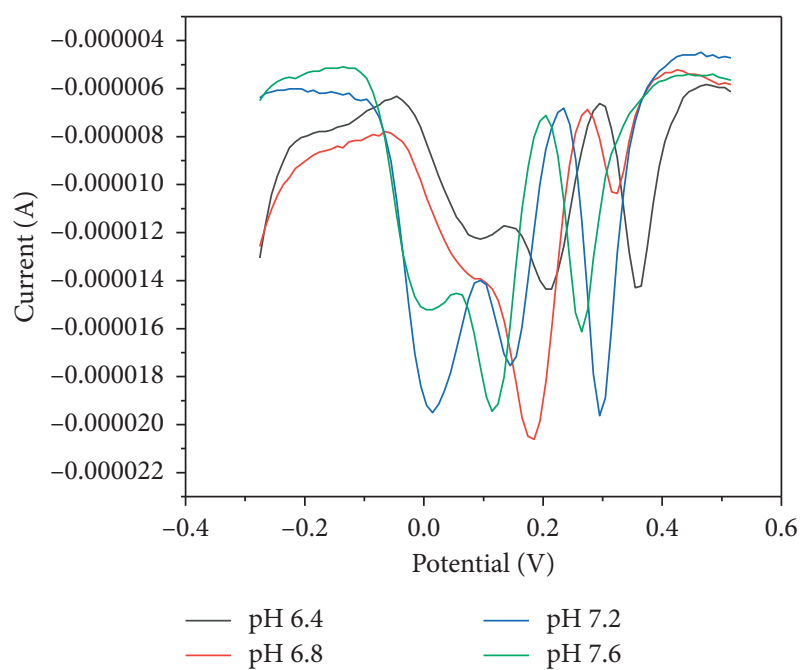

(a)

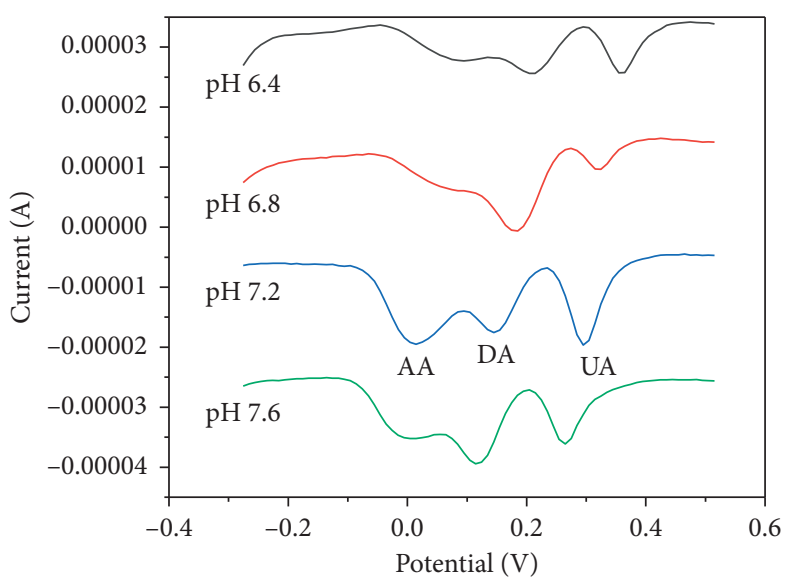

(b)

FIGUre 2: (a) DPVs of $0.75 \mathrm{mM}$ AA, $30 \mu \mathrm{M}$ DA, and 1.25 mM UA at PdNPs/rGO/GCE at various pH values (black: 6.4; red: 6.8; blue: 7.2; green: 7.6); (b) DPV curves after translation.

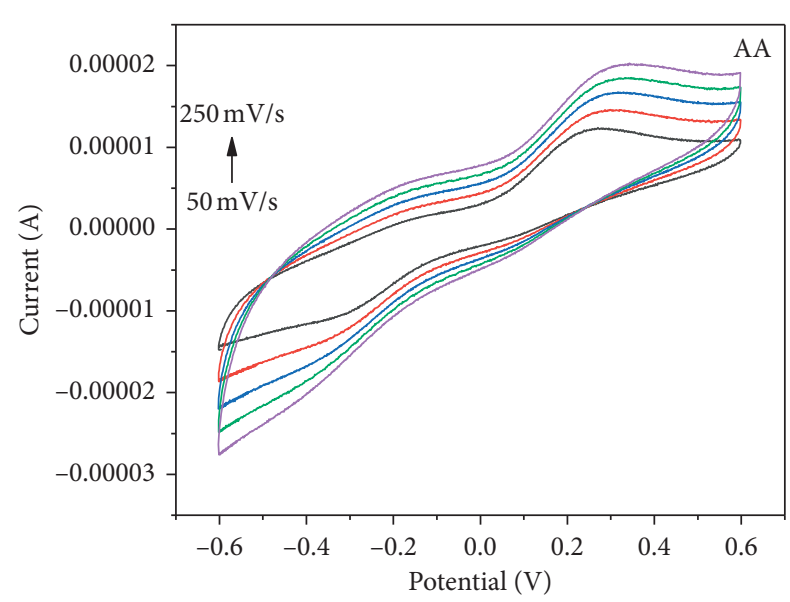

(a)

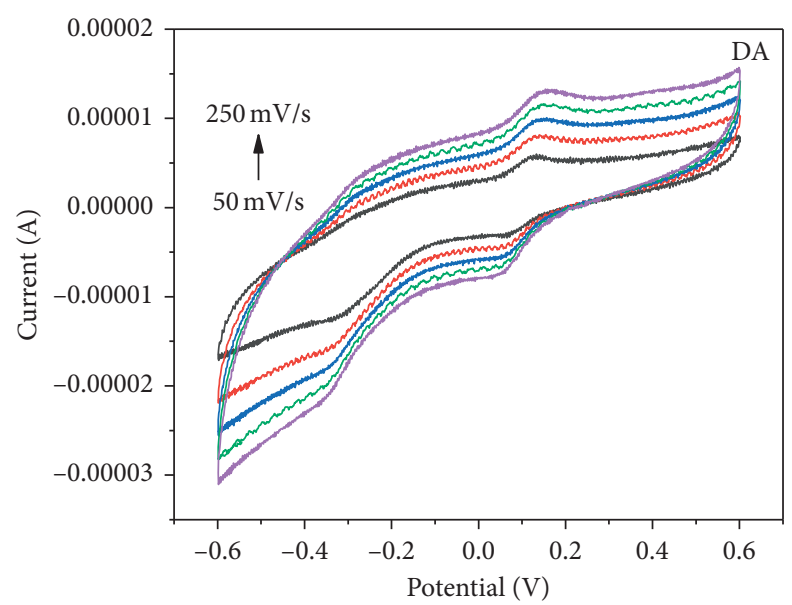

(c)

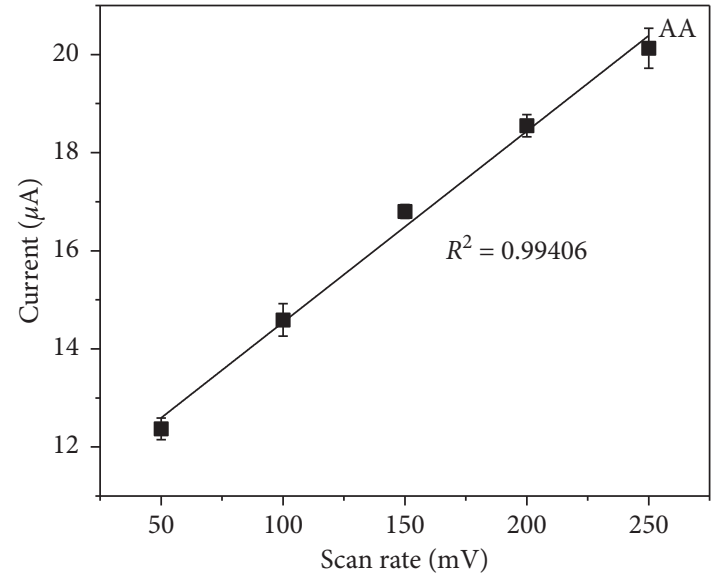

(b)

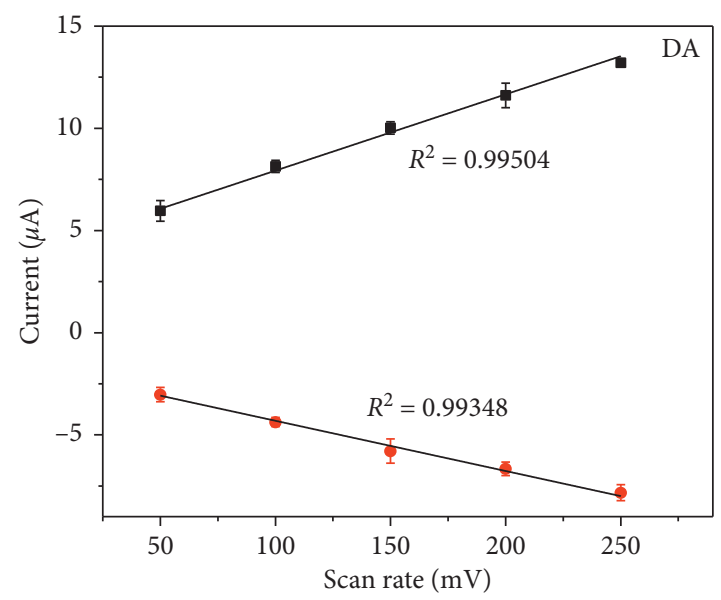

(d)

Figure 3: Continued. 


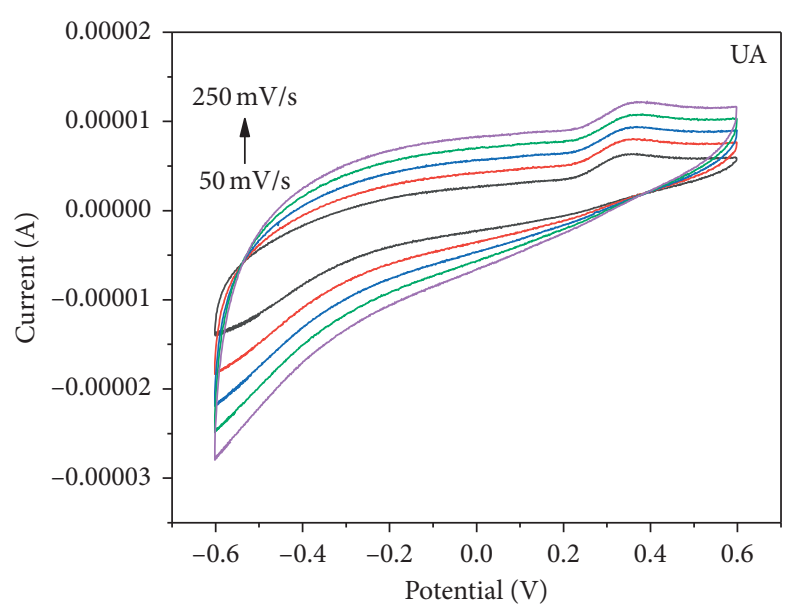

(e)

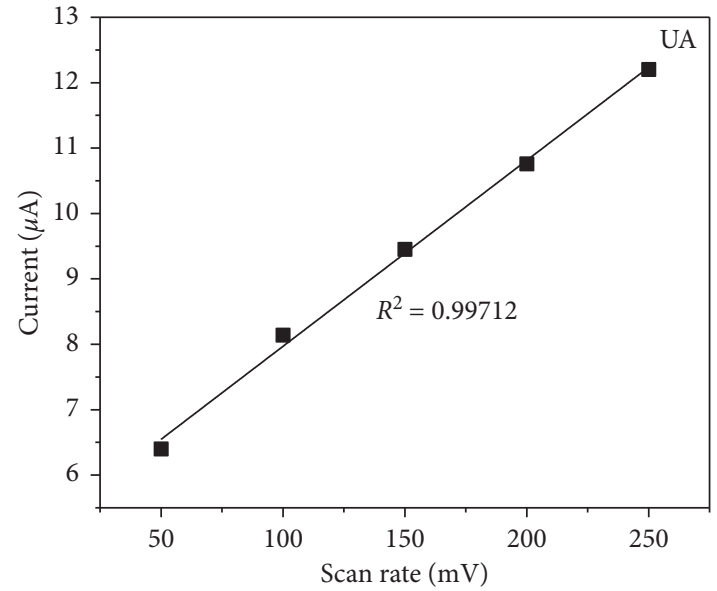

(f)

FIgUre 3: CV voltammograms of AA (a), DA (c), and UA (e) on PdNPs/rGO/GCE at 50, 100, 150, 200, and 250 mV.s ${ }^{-1}$ scan rates; relationship between the peak current of (b) AA, (d) DA, and (f) UA and the scan rates.

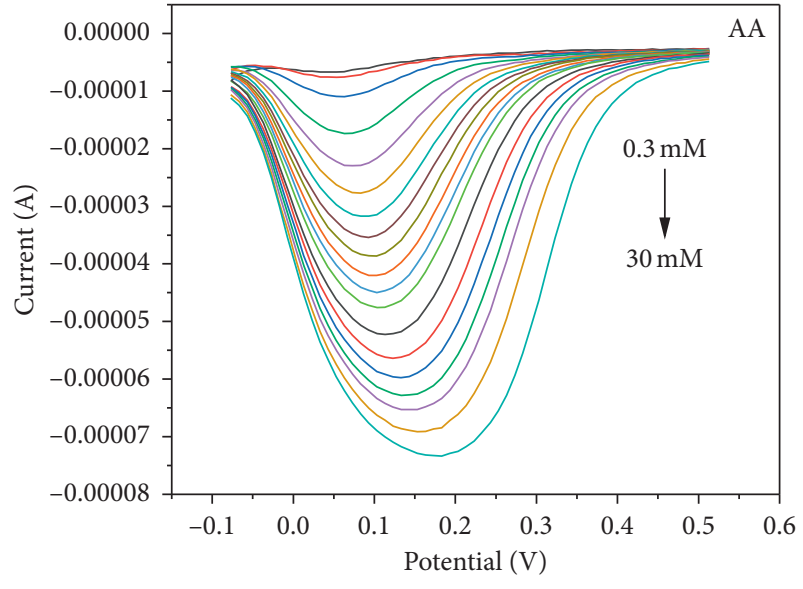

(a)

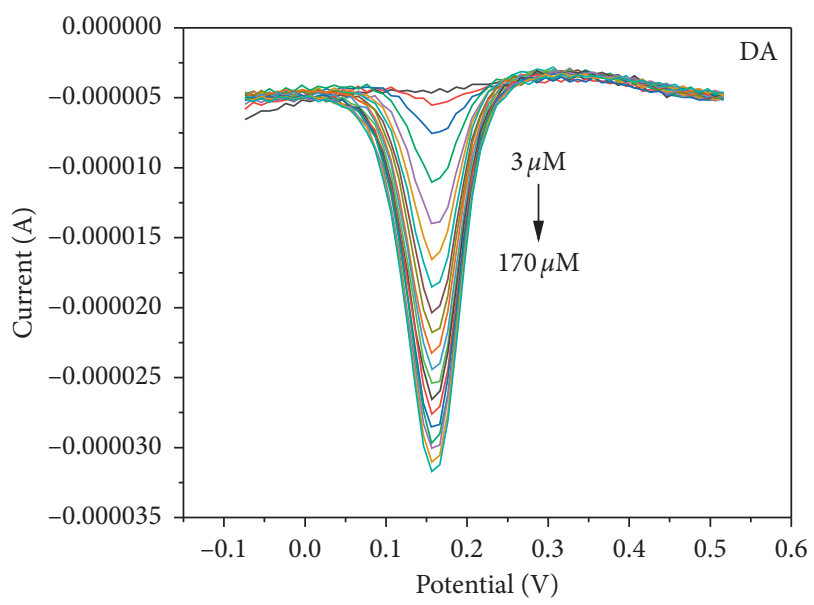

(c)

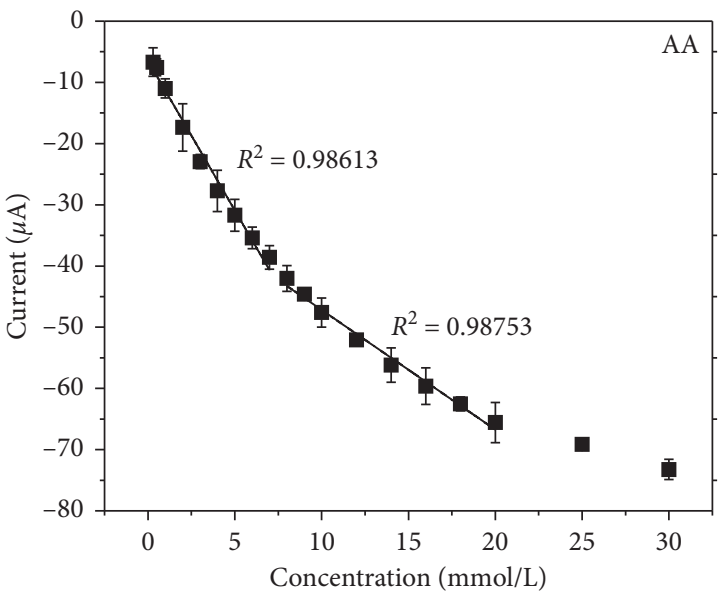

(b)

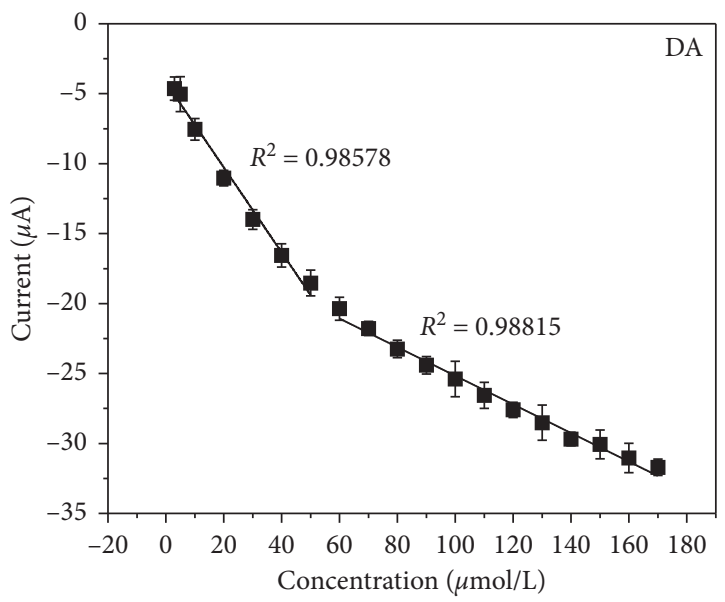

(d)

Figure 4: Continued. 


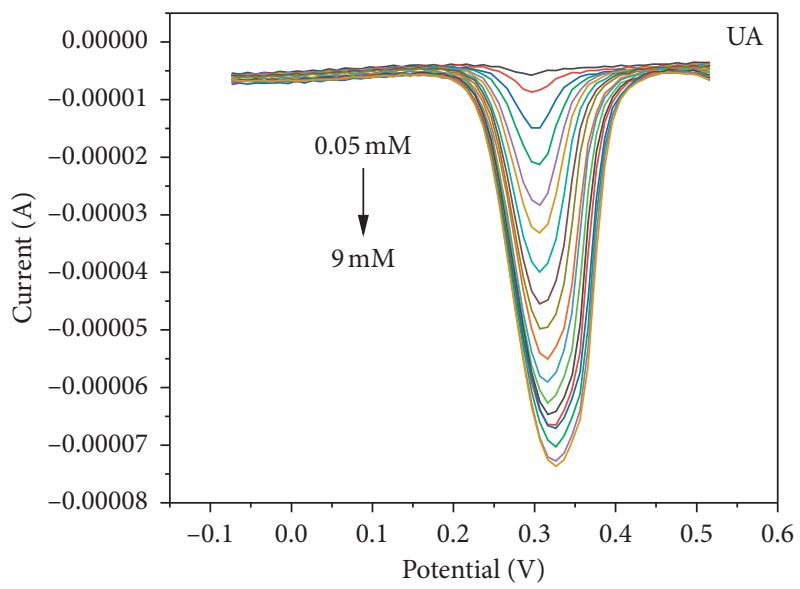

(e)

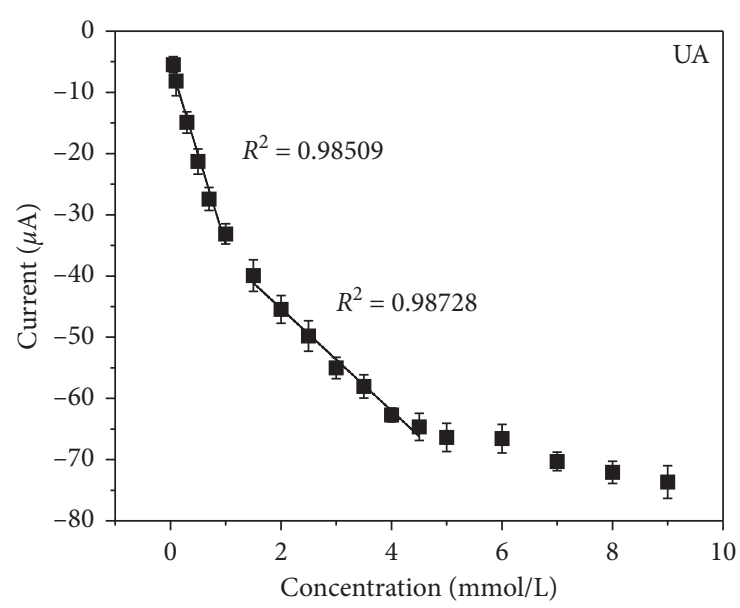

(f)

FIGURe 4: DPVs of different concentrations of (a) AA, (c) DA, and (e) UA on PdNPs/rGO/GCE in 0.1 M PB (pH 7.2); calibration plots for (b) $\mathrm{AA},(\mathrm{d}) \mathrm{DA}$, and (f) UA.

As can be seen from Figure 4, at PdNPs/rGO/GCE, the peak current signals of AA, DA, and UA were all gradually increased with their rising levels and achieve a good linear relationship in the concentration ranges of $0.3-7 \mathrm{mM}$ and $8-20 \mathrm{mM}, 3-50 \mu \mathrm{M}$ and $60-170 \mu \mathrm{M}$, and $0.05-1 \mathrm{mM}$ and $1.5-4.5 \mathrm{mM}$ with detection limits of $0.1 \mathrm{mM}, 1 \mu \mathrm{M}$, and $16.67 \mu \mathrm{M}(\mathrm{S} / \mathrm{N}=3)$, respectively. In addition, from Figure 4(a), it is worth noting that, with the increase in AA concentration, the peak potential of AA shifts to the right, indicating that protons have participated in the electrode reaction process of AA [32]. Meanwhile, the peak shape of AA gradually widens, which is consistent with previous studies [33-35] that may be related to the excessive concentration of AA. At low AA levels, the local AA on the electrode surface was rapidly catalyzed, and the response was fast. At high AA concentrations, a large amount of AA was adsorbed on the electrode surface, leading to the reduction of the active sites on the surface of electrode prolonging the catalytic time of PdNPs/ $\mathrm{rGO} / \mathrm{GCE}$ for AA, thus slowing down the catalytic process and widening the peak shape [36]. The oxidation mechanisms of AA, DA, and UA may be inferred as follows: (1) electrostatic interaction between positive DA and negative functional groups on PdNPs/rGO/GCE surface; (2) the hydrogen bond interaction between the hydroxyl groups of AA, DA, and UA and the oxygen-containing functional groups on the surface of PdNPs/ rGO/GCE.

Figures 5 and 6 exhibit the selective and simultaneous detection results of $\mathrm{AA}, \mathrm{DA}$, and UA. It is worth mentioning that the selective detection was carried out by changing the concentrations of target species while keeping the other two substances at constant in a mixture of AA, DA, and UA. As can be observed, there exists three well-separated potential peaks corresponding to AA, DA, and UA either in selective or simultaneous detection, and the presence of the other two species did not produce significant impact on the current signal of the target analyte, suggesting that PdNPs/rGO/ GCE possesses good separation capacity toward AA, DA, and UA. The detailed results are presented in Table 1. Compared with individual detection, the linear range of AA,
$\mathrm{DA}$, and UA under the same concentration range and the sensitivity of PdNPs/rGO/GCE toward these three analytes all produced a negligible change either in selective or simultaneous detection.

In addition, it can be observed from Figure 5(a) that, with the increase in AA concentration, in addition to the increasing AA current, the detection currents of DA and UA were also increased, which is consistent with previous literatures $[28,29,37-41]$ that can be related to the adsorption of DA and UA on the electrode surface [42]. The higher concentration of AA on electrode surface continuously reacts with the oxidation products of DA and UA, resulting in the regeneration of $\mathrm{DA}$ and $\mathrm{UA}$, thus increasing the current $[43,44]$. Moreover, from Figures 4(a), $5(\mathrm{a})$, and 6(a), it is worthy to note that the oxidation voltages of AA in these three experiments were not the same, which may be related to the concentration range of $\mathrm{AA}$ and the interaction between $\mathrm{AA}$ and $\mathrm{DA}$ and UA $[43,44]$.

As shown in Table 2, although most of previous works showed higher sensitivity toward AA and UA than PdNPs/ rGO/GCE, from the perspective of sensitivity toward DA and linear range, PdNPs/rGO/GCE still occupies a unique advantage in the simultaneous detection of AA, DA, and UA.

The above results showed that the developed sensor has a good application value in the detection of AA, DA, and UA.

3.5. Reproducibility and Stability of the Sensor. Reproducibility and stability are also crucial indicators for the evaluation of the electrochemical performances of the developed sensor.

The reproducibility of PdNPs/rGO/GCE was studied by DPV using six sensors that were prepared under the same conditions to detect $1 \mathrm{mM} \mathrm{AA}, 10 \mu \mathrm{M} \mathrm{DA}$, and $2.5 \mathrm{mM} \mathrm{UA}$ in $0.1 \mathrm{MPB}$, respectively, and the results were exhibited in the form of histogram (Figure $7(\mathrm{a})$ ). The relative standard 


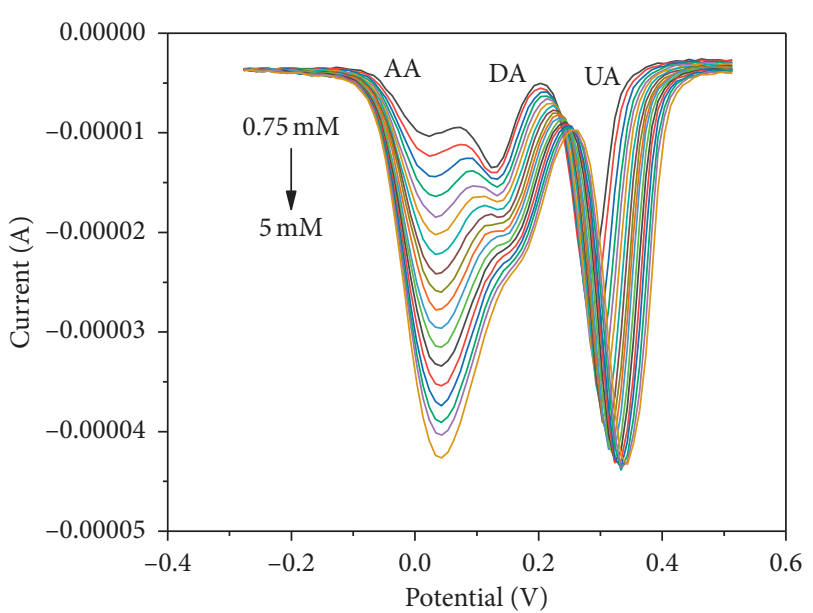

(a)

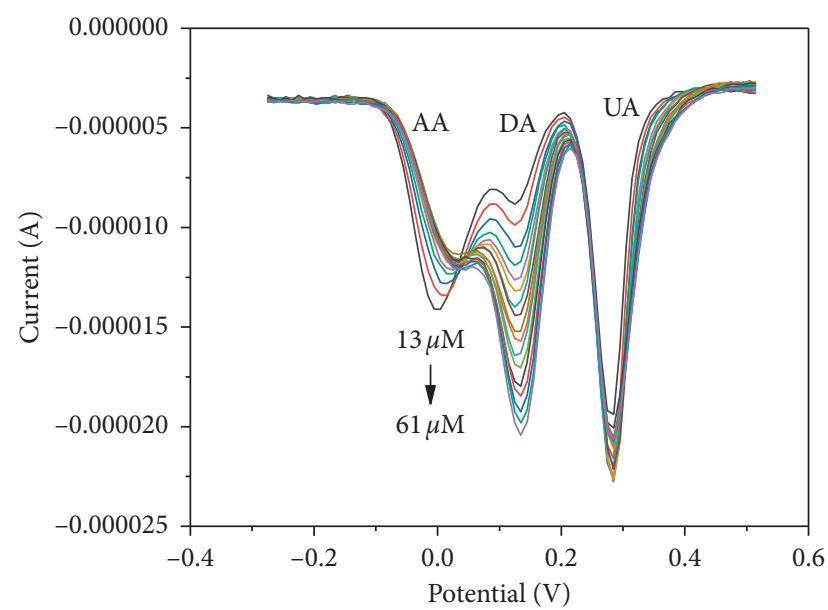

(c)

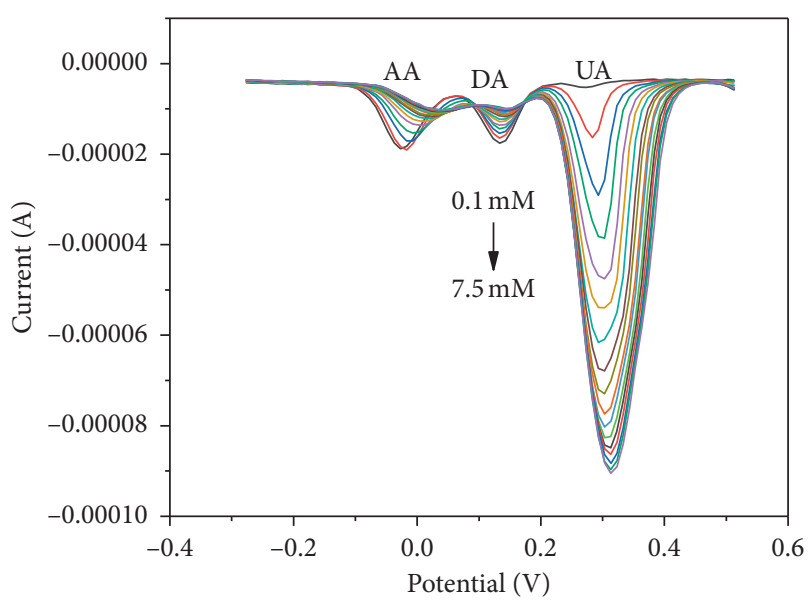

(e)

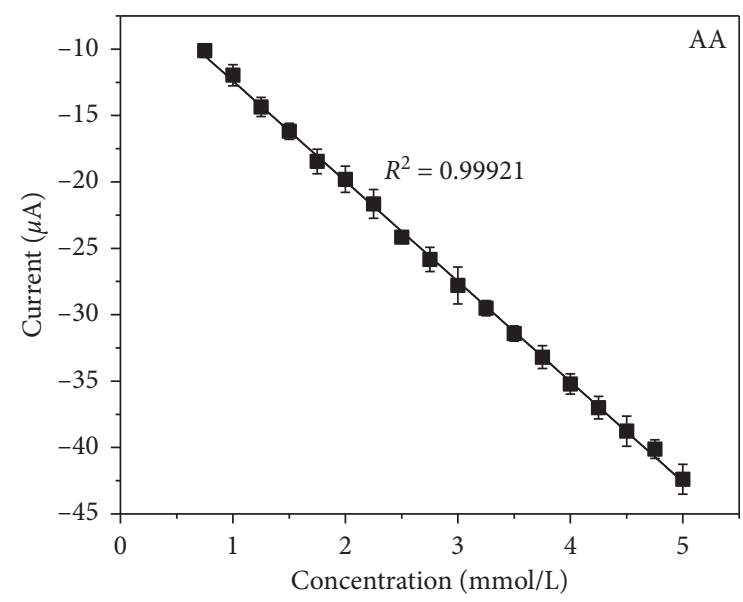

(b)

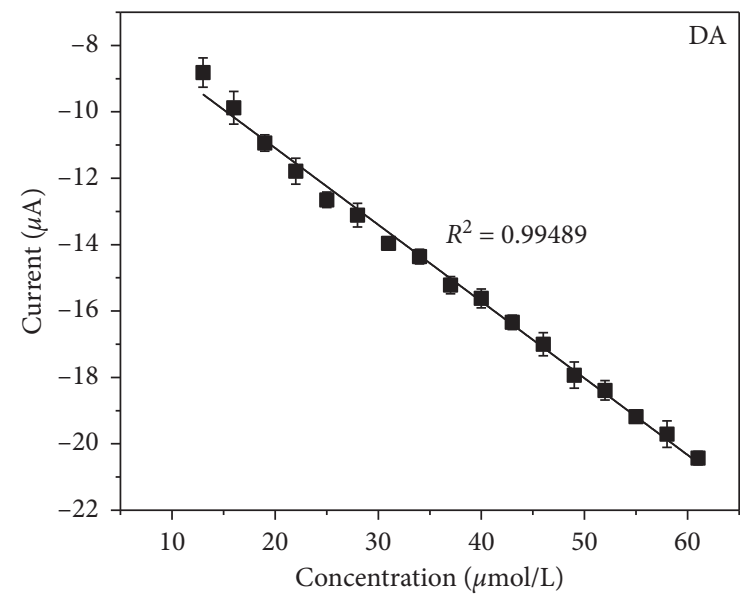

(d)

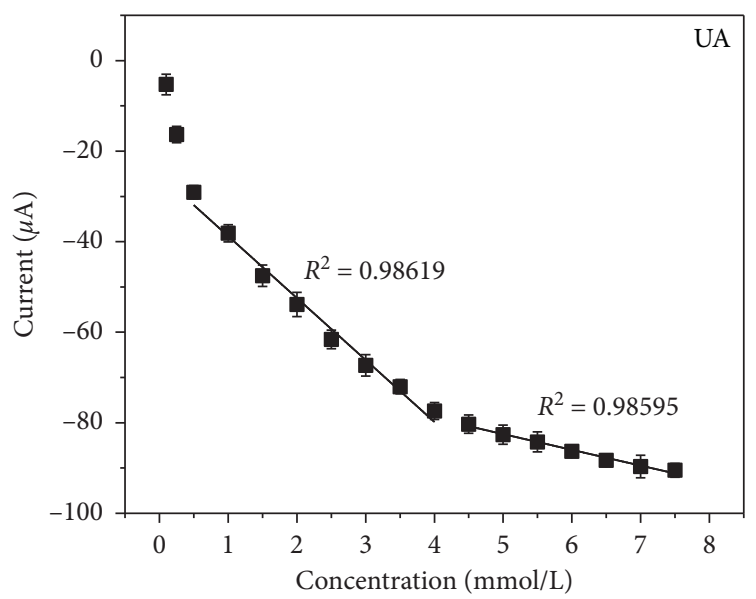

(f)

FIGURE 5: DPVs of different concentrations of (a) AA in the presence of $20 \mu \mathrm{M}$ DA and $0.5 \mathrm{mM}$ UA, (c) DA in the presence of $1.5 \mathrm{mM}$ AA and $0.5 \mathrm{mM}$ UA, and (e) UA in the presence of $0.75 \mathrm{mM} \mathrm{AA}$ and $10 \mu \mathrm{M}$ DA. Calibration plots for (b) AA, (d) DA, and (f) UA.

deviation (RSD) of the DPV responses of AA, DA, and UA was calculated as $0.98 \%, 2.08 \%$, and $0.6 \%$, respectively, revealing that the proposed sensor has high reproducibility.

Chronoamperometry was used to access the stability of PdNPs/rGO/GCE toward $1 \mathrm{mM} \mathrm{AA}, 20 \mu \mathrm{M}$ DA, and $0.5 \mathrm{mM}$
UA in $0.1 \mathrm{M}$ PB for $2000 \mathrm{~s}$ at +0.6 V. From Figures $7(\mathrm{~b})-7(\mathrm{~d})$, the current response of these three analytes reached a steady state in a short time, and the changes over a long period were negligible, which suggested that this sensor is suitable for long-term detection of AA, DA, and UA. 


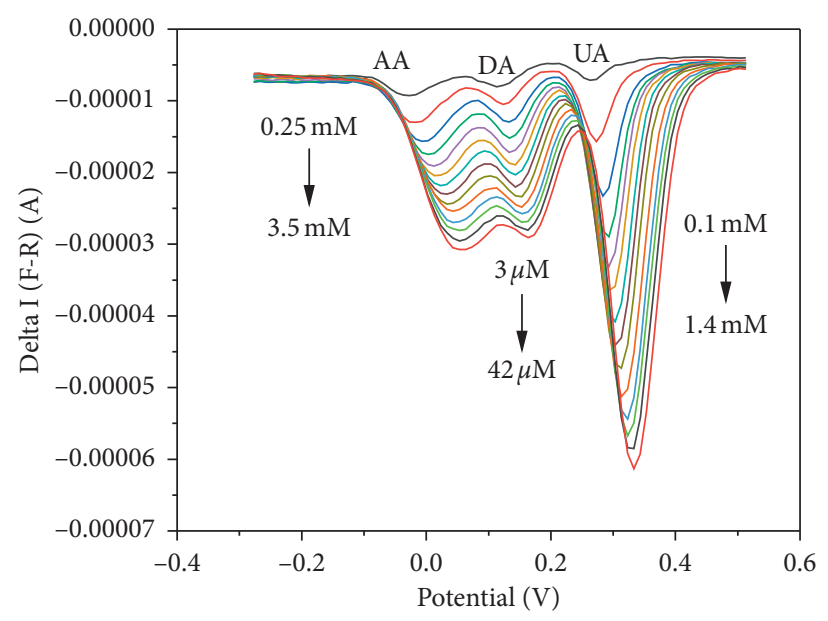

(a)

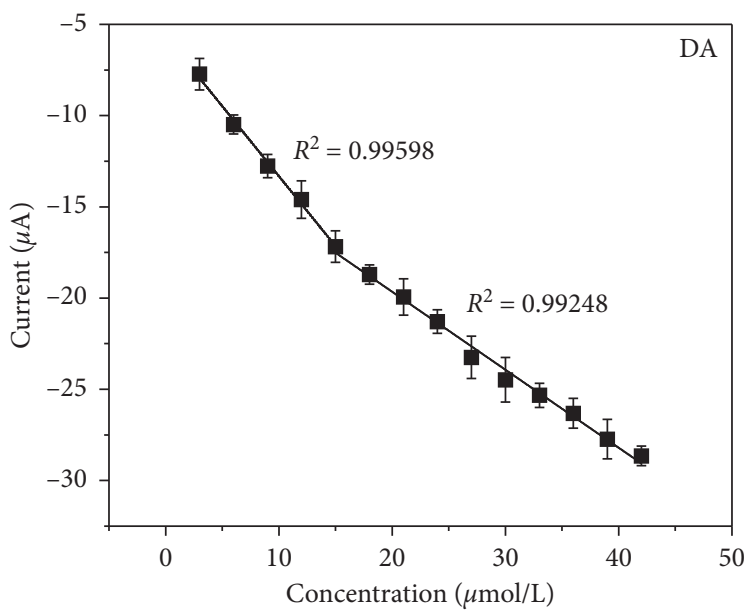

(c)

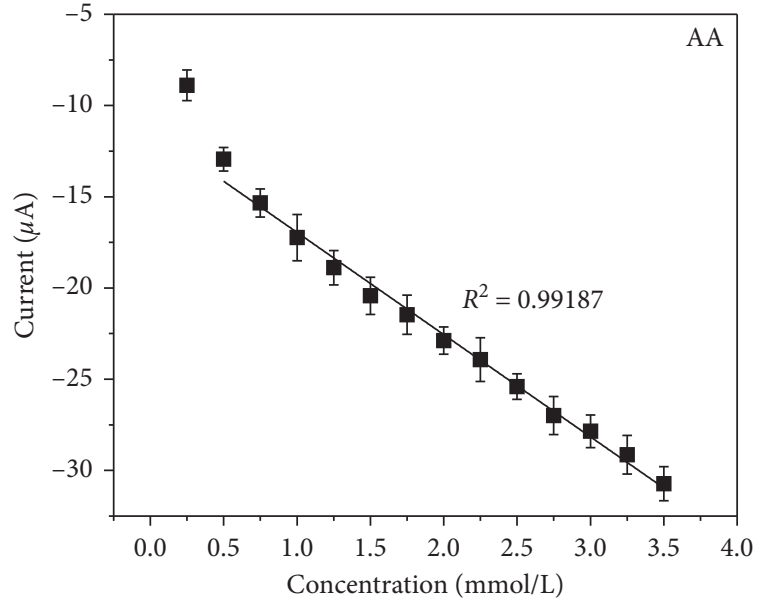

(b)

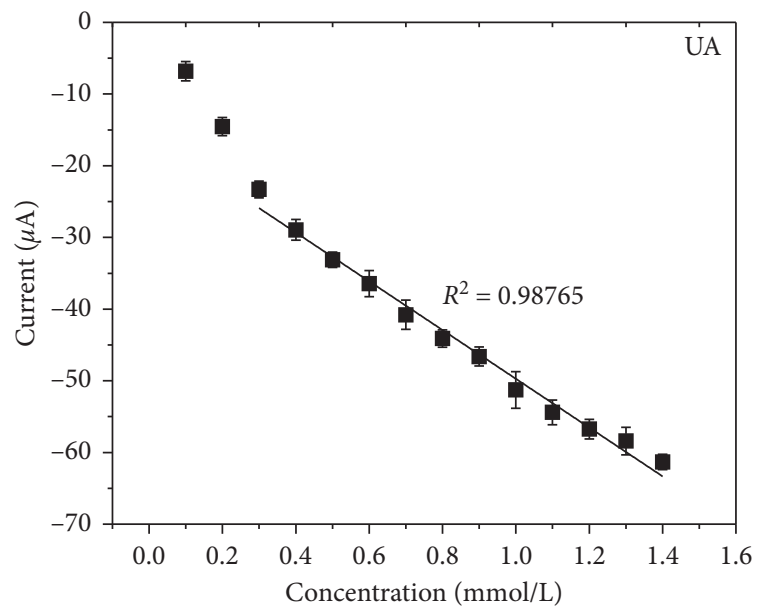

(d)

Figure 6: DPV curves of different concentrations of AA, DA, and UA (a); calibration plots for (b) AA, (c) DA, and (d) UA.

TABLe 1: Analytical parameters for individual, selective, and simultaneous detection of AA, DA, and UA at PdNPs/rGO/GCE.

\begin{tabular}{lcccc}
\hline Analytical parameter & Analyte & Individual detection & Selective detection & Simultaneous detection \\
\hline \multirow{3}{*}{ Linear range $(\mu \mathrm{M})$} & AA & $300-7000,8000-20000$ & $750-5000$ & $500-3500$ \\
& DA & $3-50,60-170$ & $13-61$ & $3-15,15-42$ \\
\multirow{2}{*}{ Sensitivity $\left(\mu \mathrm{A} \cdot \mu \mathrm{M}^{-1} \cdot \mathrm{cm}^{-2}\right)$} & UA & $50-1000,1500-4500$ & $500-4000,4500-7500$ & $300-1400$ \\
& AA & $0.069,0.028$ & 0.107 & 0.079 \\
& DA & $4.300,1.443$ & 3.254 & $10.893,6.083$ \\
& UA & $0.416,0.118$ & $0.194,0.049$ & 0.481 \\
\hline
\end{tabular}

3.6. Study of Anti-Interference Ability. Lastly, to evaluate the anti-interference ability of PdNPs/rGO/GCE, the interference of $\mathrm{Na}^{+}$(d), $\mathrm{Cl}^{-}$(e), $\mathrm{Mg}^{2+}$ (f), $\mathrm{SO}^{2-}(\mathrm{g})$, and glucose (h) with 100-fold concentration in the detection of $1 \mathrm{mM} \mathrm{AA}$ (a), $50 \mu \mathrm{M}$ DA (b), and $0.1 \mathrm{mM}$ UA (c) in $0.1 \mathrm{MPB}$ was conducted by chronoamperometry at a constant potential of $+0.6 \mathrm{~V}$ for $800 \mathrm{~s}$. As shown in Figure 8, with the addition of AA, DA, and UA, the current signal of PdNPs/rGO/GCE increased rapidly with response times of $5 \mathrm{~s}, 5 \mathrm{~s}$, and $3 \mathrm{~s}$, respectively, and the interferents did not produce obvious effects on the current signal of AA, DA, and UA. As a result, this proposed sensor was of excellent anti-interference ability and practical application value.

3.7. Real Samples Detection. In order to demonstrate the applicability of the proposed method, different concentrations of AA, DA, and UA are doped into the human serum samples by the standard addition method. The DPV experimental results are shown in Table S1. The recoveries of the spiked samples were 
TABle 2: Comparison of different electrodes in the simultaneous detection of AA, DA, and UA.

\begin{tabular}{|c|c|c|c|c|c|}
\hline \multirow[t]{2}{*}{ Electrode } & \multirow[t]{2}{*}{$\mathrm{pH}$} & \multicolumn{3}{|c|}{$\begin{array}{c}\text { Linear range }(\mu \mathrm{M}) \\
\text { Sensitivity }\left(\mu \mathrm{A} \cdot \mu \mathrm{M}^{-1} \cdot \mathrm{cm}^{-2}\right)\end{array}$} & \multirow[t]{2}{*}{ Ref. } \\
\hline & & AA & DA & UA & \\
\hline MgO nanobelts/GCE & 5.0 & $\begin{array}{c}2.5-15,25-150 \\
0.198,0.028\end{array}$ & $\begin{array}{c}0.125-7.5 \\
7.908\end{array}$ & $\begin{array}{c}0.5-3,5-30 \\
2.83,0.962\end{array}$ & {$[30]$} \\
\hline $\mathrm{SnO}_{2} /$ chitosan/GCE & 7.0 & $\begin{array}{c}20-220 \\
0.127\end{array}$ & $\begin{array}{l}0.1-18 \\
2.773\end{array}$ & $\begin{array}{c}1-100 \\
2.391\end{array}$ & [45] \\
\hline $3 \mathrm{DGH}^{\mathrm{a}}-\mathrm{AuNPs}{ }^{\mathrm{b}} / \mathrm{GCE}$ & 7.0 & $\begin{array}{c}1.0-700 \\
0.217\end{array}$ & $\begin{array}{c}0.2-30 \\
3.897\end{array}$ & $\begin{array}{l}1-60 \\
1.703\end{array}$ & {$[46]$} \\
\hline $\mathrm{AuNPs}^{\mathrm{b}} @ \mathrm{MoS}_{2}$ nanosheets/GCE & 4.0 & $\begin{array}{c}12-800 \\
0.481\end{array}$ & $\begin{array}{c}10-300 \\
0.979\end{array}$ & $\begin{array}{c}8-900 \\
0.465\end{array}$ & {$[47]$} \\
\hline $\mathrm{Pd}_{3} \mathrm{Pt}_{1}{ }^{\mathrm{c}} / \mathrm{PDDA}^{\mathrm{d}}-\mathrm{rGO} / \mathrm{GCE}$ & 7.4 & $\begin{array}{l}40-1200 \\
0.359\end{array}$ & $\begin{array}{c}4-200 \\
0.639\end{array}$ & $\begin{array}{c}4-400 \\
0.498\end{array}$ & {$[48]$} \\
\hline $\mathrm{CB}^{\mathrm{e}} / \mathrm{GCE}$ & 7.0 & $\begin{array}{l}1.91-37.8 \\
0.214\end{array}$ & $\begin{array}{l}0.599-11.8 \\
1.570\end{array}$ & $\begin{array}{c}1.01-14 \\
0.680\end{array}$ & {$[49]$} \\
\hline Pt@NP-AuSn ${ }^{\mathrm{f}} / \mathrm{CFP}{ }^{\mathrm{g}}$ & 7.0 & $\begin{array}{l}200-1200 \\
0.0004\end{array}$ & $\begin{array}{c}0.5-10 \\
0.0017\end{array}$ & $\begin{array}{c}25-500 \\
0.0003\end{array}$ & {$[50]$} \\
\hline $\mathrm{PdNPs} / \mathrm{rGO} / \mathrm{GCE}$ & 7.2 & $\begin{array}{l}500-3500 \\
0.079\end{array}$ & $\begin{array}{l}3-15,15-42 \\
10.893,6.083\end{array}$ & $\begin{array}{l}300-1400 \\
0.481\end{array}$ & This work \\
\hline
\end{tabular}

a: three dimensional graphene hydrogel; b: gold nanoparticles; c: Pd-Pt bimetallic nanoparticles; d: poly(diallyldimethylammonium chloride); e: nanostructured carbon black; f: Pt nanoparticle-modified nanoporous AuSn; g: Ni-buffered flexible carbon fiber paper.
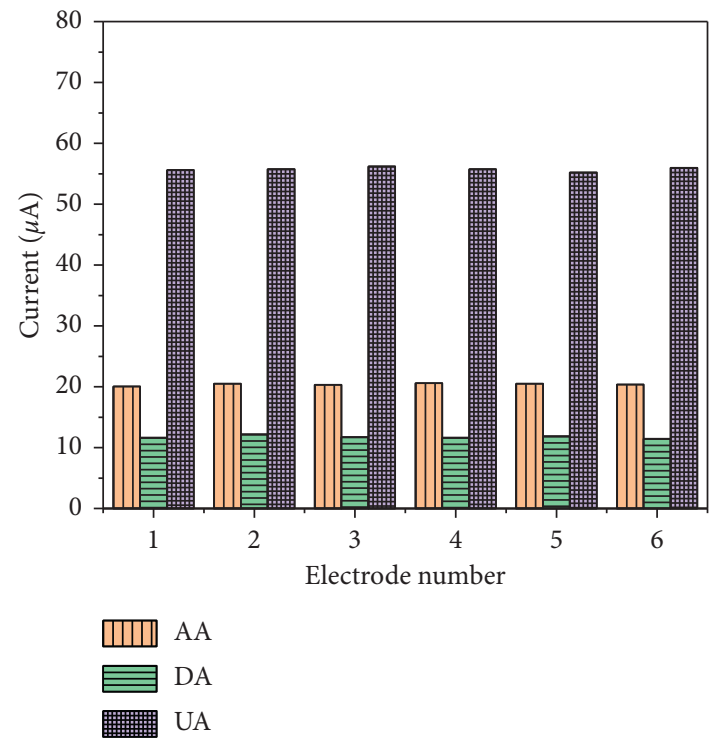

(a)

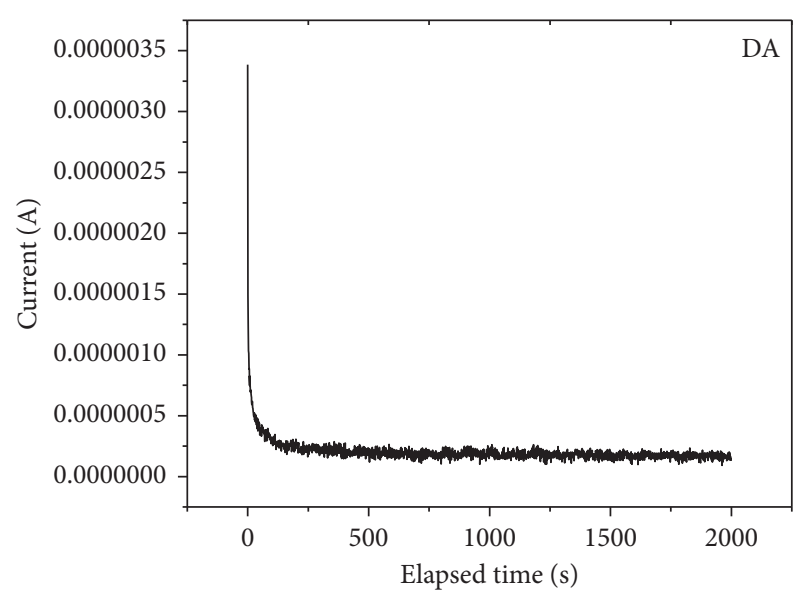

(c)

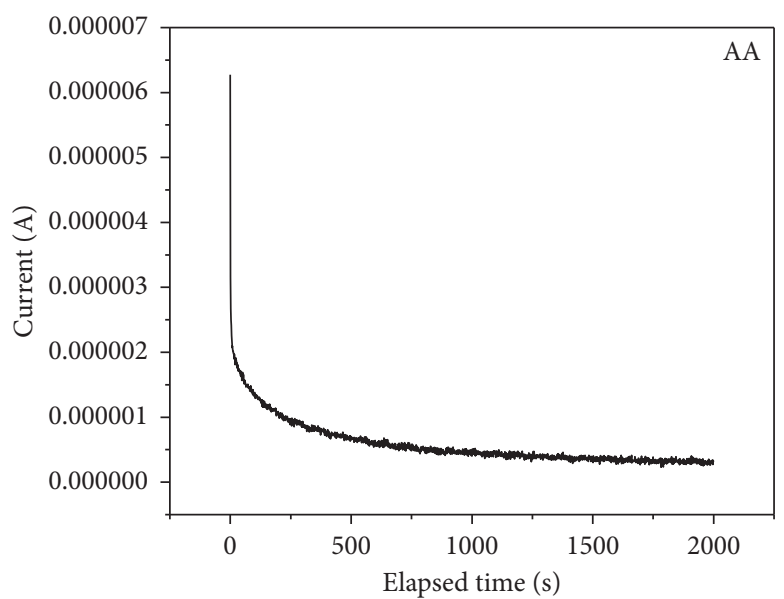

(b)

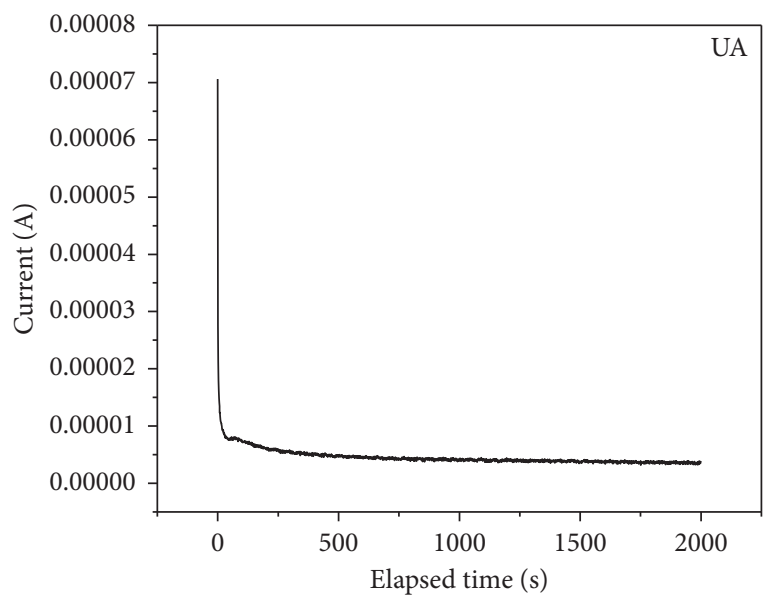

(d)

Figure 7: (a) Reproducibility of CQDs-rGO/GCE; stability of (b) $1 \mathrm{mM} \mathrm{AA,} \mathrm{(c)} 20 \mu \mathrm{M}$ DA, and (d) $0.5 \mathrm{mM}$ UA 


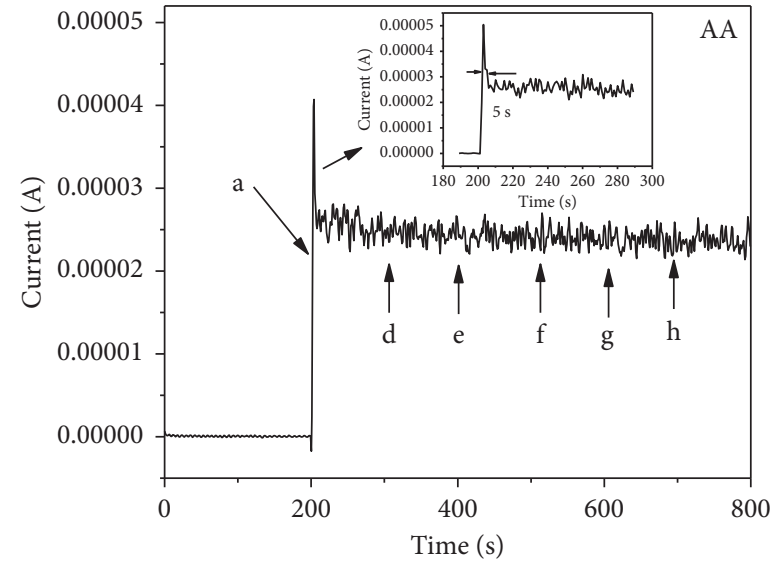

(a)

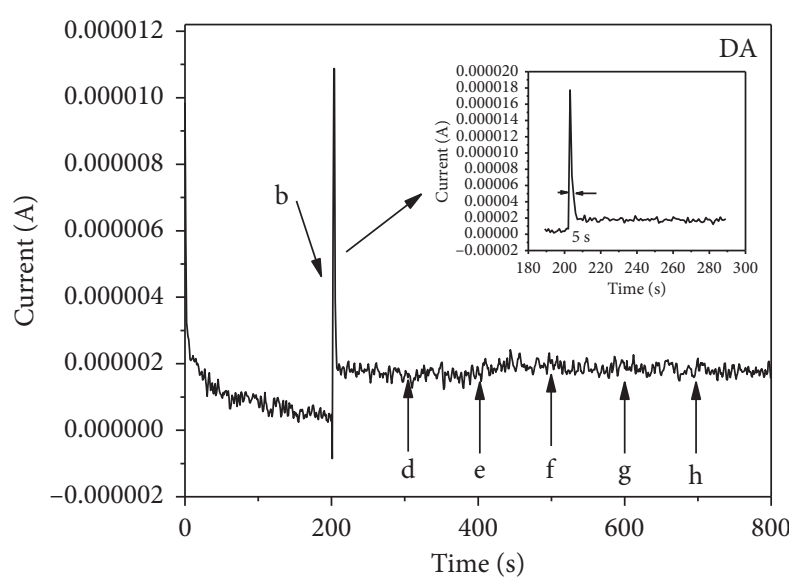

(b)

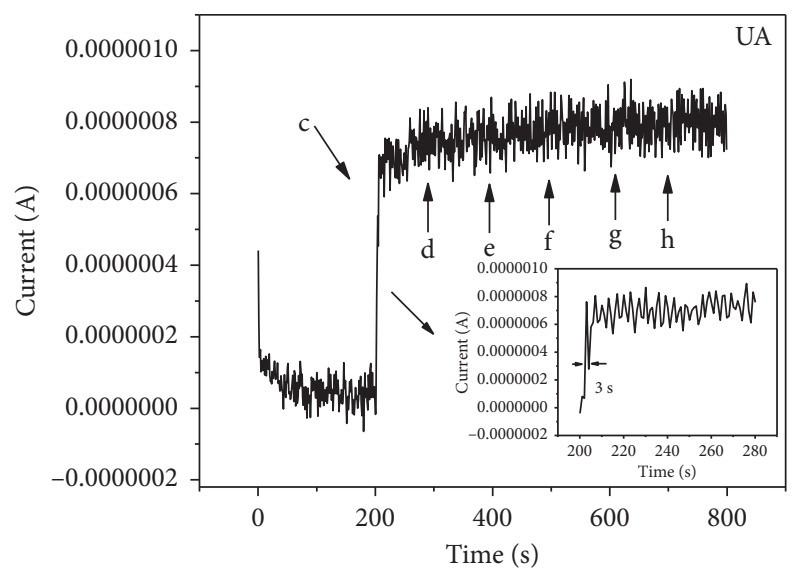

(c)

Figure 8: Amperometric responses of $1 \mathrm{mM}$ AA (a), $50 \mu \mathrm{M}$ DA (b), and $0.1 \mathrm{mM}$ UA (c) in the presence of 100-fold concentration of interferents.

detected within the range of $96.6 \%-108.5 \%$, suggesting the applicability of the prepared sensor to real samples.

\section{Conclusions}

In summary, this paper has proposed a novel approach for the synthesis of PdNPs/rGO nanocomposite by two-step CV electrodeposition; the increased surface area of as-prepared material has contributed to improve the contact probability between electrode surface and analytes, thus elevating the catalytic activity of the modified electrode, which was confirmed using CV and EIS. After optimizing the experimental conditions, the sensor showed excellent separation ability and fast response for AA, DA, and UA and has strong anti-interference ability for some common interfering substances. Besides, good reproducibility and stability were also obtained by this sensor. The above results revealed that PdNPs/rGO/GCE can be a good candidate in the sensing application of $\mathrm{AA}, \mathrm{DA}$, and $\mathrm{UA}$ in the future.

\section{Data Availability}

The generated or analyzed data used to support the findings of this study are included within the article.

\section{Conflicts of Interest}

The authors declare that they have no conflicts of interest.

\section{Acknowledgments}

This study was financially supported by the National Key R\&D Program of China (no. 2019YFC1709000), National Natural Science Foundation of China (NSFC) (nos. 81973944 and 81503636), National S\&T Major Project (no. 2018ZX09201011), and Youth Talent Promotion Project of the China Association for Science and Technology (no. 20192021ZGZJXH-QNRC001).

\section{Supplementary Materials}

Figure S1: EDS characterization of PdNPs/rGO nanocomposites. Figure S2: CV characterization of bare GCE (a), rGO/GCE (b), and PdNPs/rGO/GCE (c) in $20 \mathrm{mM}$ potassium ferricyanide solution containing $0.1 \mathrm{M} \mathrm{KCl}$. Table S1: detection of AA, DA, and UA in real samples $(n=3)$. (Supplementary Materials) 


\section{References}

[1] D. Wen, S. Guo, S. Dong, and E. Wang, "Ultrathin Pd nanowire as a highly active electrode material for sensitive and selective detection of ascorbic acid," Biosensors and Bioelectronics, vol. 26, no. 3, pp. 1056-1061, 2010.

[2] L. Yang, N. Huang, Q. Lu et al., "A quadruplet electrochemical platform for ultrasensitive and simultaneous detection of ascorbic acid, dopamine, uric acid and acetaminophen based on a ferrocene derivative functional $\mathrm{Au}$ NPs/carbon dots nanocomposite and graphene," Analytica Chimica Acta, vol. 903, pp. 69-80, 2016.

[3] X. Zhang, L.-X. Ma, and Y.-C. Zhang, "Electrodeposition of platinum nanosheets on C 60 decorated glassy carbon electrode as a stable electrochemical biosensor for simultaneous detection of ascorbic acid, dopamine and uric acid," Electrochimica Acta, vol. 177, pp. 118-127, 2015.

[4] K. Ghanbari and N. Hajheidari, "ZnO-CuxO/polypyrrole nanocomposite modified electrode for simultaneous determination of ascorbic acid, dopamine, and uric acid," Analytical Biochemistry, vol. 473, pp. 53-62, 2015.

[5] F. Yang, J. Wang, Y. Cao, L. Zhang, and X. Zhang, "A highly sensitive ascorbic acid sensor based on carbon-supported CoPd nanoparticles," Sensors and Actuators B: Chemical, vol. 205, pp. 20-25, 2014.

[6] X. Zhang, Y. Cao, S. Yu, F. Yang, and P. Xi, "An electrochemical biosensor for ascorbic acid based on carbon-supported PdNi nanoparticles," Biosensors and Bioelectronics, vol. 44, pp. 183-190, 2013.

[7] H.-M. Wang, C.-C. Wang, A.-J. Wang et al., "Green synthesis of $\mathrm{Pd}$ nanocones as a novel and effective electrochemiluminescence illuminant for highly sensitive detection of dopamine," Sensors and Actuators B: Chemical, vol. 281, pp. 588-594, 2019.

[8] H. Bagheri, N. Pajooheshpour, B. Jamali, S. Amidi, A. Hajian, and H. Khoshsafar, "A novel electrochemical platform for sensitive and simultaneous determination of dopamine, uric acid and ascorbic acid based on $\mathrm{Fe}_{3} \mathrm{O}_{4} \mathrm{SnO}_{2} \mathrm{Gr}$ ternary nanocomposite," Microchemical Journal, vol. 131, pp. 120-129, 2017.

[9] M. Wang, Y. Gao, J. Zhang, and J. Zhao, "Highly dispersed carbon nanotube in new ionic liquid-graphene oxides aqueous dispersions for ultrasensitive dopamine detection," Electrochimica Acta, vol. 155, pp. 236-243, 2015.

[10] G. Li, Y. Xia, Y. Tian et al., "Review-recent developments on graphene-based electrochemical sensors toward nitrite," Journal of the Electrochemical Society, vol. 166, no. 12, pp. B881-B895, 2019.

[11] Q. Li, Y. Xia, X. Wan et al., "Morphology-dependent $\mathrm{MnO}_{2}$ / nitrogen-doped graphene nanocomposites for simultaneous detection of trace dopamine and uric acid," Materials Science and Engineering: C, vol. 109, p. 110615, 2020.

[12] X. Wan, S. Yang, Z. Cai et al., "Facile synthesis of $\mathrm{MnO}_{2}$ nanoflowers/N-doped reduced graphene oxide composite and its application for simultaneous determination of dopamine and uric acid," Nanomaterials, vol. 9, no. 6, p. 847, 2019.

[13] S. Daemi, A. A. Ashkarran, A. Bahari, and S. Ghasemi, "Fabrication of a gold nanocage/graphene nanoscale platform for electrocatalytic detection of hydrazine," Sensors and Actuators B: Chemical, vol. 245, pp. 55-65, 2017.

[14] N. Tukimin, J. Abdullah, and Y. Sulaiman, "Electrodeposition of poly(3,4-ethylenedioxythiophene)/reduced graphene oxide/manganese dioxide for simultaneous detection of uric acid, dopamine and ascorbic acid," Journal of Electroanalytical Chemistry, vol. 820, pp. 74-81, 2018.
[15] Q. He, J. Liu, X. Liu et al., "A promising sensing platform toward dopamine using $\mathrm{MnO}_{2}$ nanowires/electro-reduced graphene oxide composites," Electrochimica Acta, vol. 296, pp. 683-692, 2019.

[16] C. Mu, H. Lu, J. Bao, and Q. Zhang, "Visual colorimetric 'turn-off biosensor for ascorbic acid detection based on hypochlorite-3,3',5,5',-Tetramethylbenzidine system," Spectrochimica Acta Part A: Molecular and Biomolecular Spectroscopy, vol. 201, pp. 61-66, 2018.

[17] E. Fazio, S. Spadaro, M. Bonsignore et al., "Molybdenum oxide nanoparticles for the sensitive and selective detection of dopamine," Journal of Electroanalytical Chemistry, vol. 814, pp. 91-96, 2018.

[18] T. Rohani and M. A. Taher, "Novel functionalized multiwalled carbon nanotube-glassy carbon electrode for simultaneous determination of ascorbic acid and uric acid," Arabian Journal of Chemistry, vol. 11, no. 2, pp. 214-220, 2018.

[19] Q. Zhang, Z. Mao, K. Wang, N. T. S. Phan, and F. Zhang, "Microwave-assisted aqueous carbon-carbon cross-coupling reactions of aryl chlorides catalysed by reduced graphene oxide supported palladium nanoparticles," Green Chemistry, vol. 22, no. 10, pp. 3239-3247, 2020.

[20] B. Murugesan, N. Pandiyan, M. Arumugam et al., "Fabrication of palladium nanoparticles anchored polypyrrole functionalized reduced graphene oxide nanocomposite for antibiofilm associated orthopedic tissue engineering," Applied Surface Science, vol. 510, p. 145403, 2020.

[21] A. Wong, A. M. Santos, R. Da Fonseca Alves, F. C. Vicentini, O. Fatibello-Filho, and M. Del Pilar Taboada Sotomayor, "Simultaneous determination of direct yellow 50, tryptophan, carbendazim, and caffeine in environmental and biological fluid samples using graphite pencil electrode modified with palladium nanoparticles," Talanta, vol. 222, p. 121539, 2021.

[22] H. Li, S. Wang, F. Cui et al., "Sensitive and selective detection of puerarin based on the hybrid of reduced graphene oxide and molecularly imprinted polymer," Journal of Pharmaceutical and Biomedical Analysis, vol. 185, Article ID 113221, 2020.

[23] N. Gao, C. He, M. Ma et al., "Electrochemical co-deposition synthesis of $\mathrm{Au}-\mathrm{ZrO}_{2}$-graphene nanocomposite for a nonenzymatic methyl parathion sensor," Analytica Chimica Acta, vol. 1072, pp. 25-34, 2019.

[24] T. Wu, T. Li, Z. Liu, Y. Guo, and C. Dong, "Electrochemical sensor for sensitive detection of triclosan based on graphene/ palladium nanoparticles hybrids," Talanta, vol. 164, pp. 556-562, 2017.

[25] W. Yi, Z. Li, C. Dong, H.-W. Li, and J. Li, "Electrochemical detection of chloramphenicol using palladium nanoparticles decorated reduced graphene oxide," Microchemical Journal, vol. 148, pp. 774-783, 2019.

[26] D. R. Kulkarni, S. J. Malode, K. Keerthi Prabhu, N. H. Ayachit, R. M. Kulkarni, and N. P. Shetti, "Development of a novel nanosensor using Ca-doped $\mathrm{ZnO}$ for antihistamine drug," Materials Chemistry and Physics, vol. 246, Article ID 122791, 2020.

[27] X. Zhang, S. Yu, W. He et al., "Electrochemical sensor based on carbon-supported $\mathrm{NiCoO}_{2}$ nanoparticles for selective detection of ascorbic acid," Biosensors and Bioelectronics, vol. 55, pp. 446-451, 2014.

[28] Y. Wang, Y. Huang, B. Wang, T. Fang, J. Chen, and C. Liang, "Three-dimensional porous graphene for simultaneous detection of dopamine and uric acid in the presence of ascorbic acid," Journal of Electroanalytical Chemistry, vol. 782, pp. 76-83, 2016. 
[29] X.-B. Li, M. M. Rahman, G.-R. Xu, and J.-J. Lee, "Highly sensitive and selective detection of dopamine at poly(chromotrope 2B)-Modified glassy carbon electrode in the presence of uric acid and ascorbic acid," Electrochimica Acta, vol. 173, pp. 440-447, 2015.

[30] M. Li, W. Guo, H. Li, W. Dai, and B. Yang, "Electrochemical biosensor based on one-dimensional $\mathrm{MgO}$ nanostructures for the simultaneous determination of ascorbic acid, dopamine, and uric acid," Sensors and Actuators B: Chemical, vol. 204, pp. 629-636, 2014.

[31] S. Shrestha, R. J. Mascarenhas, O. J. D'Souza et al., “Amperometric sensor based on multi-walled carbon nanotube and poly (Bromocresol purple) modified carbon paste electrode for the sensitive determination of L-tyrosine in food and biological samples," Journal of Electroanalytical Chemistry, vol. 778, pp. 32-40, 2016.

[32] X. Chen, G. Zhang, L. Shi, S. Pan, W. Liu, and H. Pan, "Au/ $\mathrm{ZnO}$ hybrid nanocatalysts impregnated in $\mathrm{N}$-doped graphene for simultaneous determination of ascorbic acid, acetaminophen and dopamine," Materials Science and Engineering: $C$, vol. 65 , pp. 80-89, 2016.

[33] R. Sha and S. Badhulika, "Facile green synthesis of reduced graphene oxide/tin oxide composite for highly selective and ultra-sensitive detection of ascorbic acid," Journal of Electroanalytical Chemistry, vol. 816, pp. 30-37, 2018.

[34] X. Wang, Z. You, H. Sha, Y. Cheng, H. Zhu, and W. Sun, "Sensitive electrochemical detection of dopamine with a DNA/graphene bi-layer modified carbon ionic liquid electrode," Talanta, vol. 128, pp. 373-378, 2014.

[35] E. Ergün, Ș. Kart, D. K. Zeybek, and B. Zeybek, "Simultaneous electrochemical determination of ascorbic acid and uric acid using poly(glyoxal-bis(2-hydroxyanil)) modified glassy carbon electrode," Sensors and Actuators B: Chemical, vol. 224, pp. 55-64, 2016.

[36] C. Wang, Z. Xiong, P. Sun, R. Wang, X. Zhao, and Q. Wang, "Facile longitudinal unzipped multiwalled carbon nanotubes incorporated overoxidized poly(p-aminophenol) modified electrode for sensitive simultaneous determination of dopamine, uric acid and tryptophan," Journal of Electroanalytical Chemistry, vol. 801, pp. 395-402, 2017.

[37] L. Zhang, J. Feng, K.-C. Chou, L. Su, and X. Hou, "Simultaneously electrochemical detection of uric acid and ascorbic acid using glassy carbon electrode modified with chrysanthemum-like titanium nitride," Journal of Electroanalytical Chemistry, vol. 803, pp. 11-18, 2017.

[38] X. Zhang, Y.-C. Zhang, and L.-X. Ma, "One-pot facile fabrication of graphene-zinc oxide composite and its enhanced sensitivity for simultaneous electrochemical detection of ascorbic acid, dopamine and uric acid," Sensors and Actuators B: Chemical, vol. 227, pp. 488-496, 2016.

[39] K. Ghanbari and M. Moloudi, "Flower-like $\mathrm{ZnO}$ decorated polyaniline/reduced graphene oxide nanocomposites for simultaneous determination of dopamine and uric acid," Analytical Biochemistry, vol. 512, pp. 91-102, 2016.

[40] A. Savk, B. Özdil, B. Demirkan et al., "Multiwalled carbon nanotube-based nanosensor for ultrasensitive detection of uric acid, dopamine, and ascorbic acid," Materials Science and Engineering: C, vol. 99, pp. 248-254, 2019.

[41] P. S. Ganesh and B. E. K. Swamy, "Simultaneous electroanalysis of norepinephrine, ascorbic acid and uric acid using poly(glutamic acid) modified carbon paste electrode," Journal of Electroanalytical Chemistry, vol. 752, pp. 17-24, 2015.

[42] M. M. Rahman, N. S. Lopa, K. Kim, and J.-J. Lee, "Selective detection of l-tyrosine in the presence of ascorbic acid, dopamine, and uric acid at poly(thionine)-modified glassy carbon electrode," Journal of Electroanalytical Chemistry, vol. 754, pp. 87-93, 2015.

[43] C. Dincer, R. Ktaich, E. Laubender et al., "Nanocrystalline boron-doped diamond nanoelectrode arrays for ultrasensitive dopamine detection," Electrochimica Acta, vol. 185, pp. 101106, 2015.

[44] Q. Yao, H. Y. Long, L. Ma et al., "Enhanced selectivity of boron doped diamond electrodes for the detection of dopamine and ascorbic acid by increasing the film thickness," Applied Surface Science, vol. 390, pp. 882-889, 2016.

[45] S. Selvarajan, A. Suganthi, and M. Rajarajan, "A facile approach to synthesis of mesoporous $\mathrm{SnO}_{2} /$ chitosan nanocomposite modified electrode for simultaneous determination of ascorbic acid, dopamine and uric acid," Surfaces and Interfaces, vol. 7, pp. 146-156, 2017.

[46] Q. Zhu, J. Bao, D. Huo et al., "3D Graphene hydrogel-gold nanoparticles nanocomposite modified glassy carbon electrode for the simultaneous determination of ascorbic acid, dopamine and uric acid," Sensors and Actuators B: Chemical, vol. 238, pp. 1316-1323, 2017.

[47] H. L. Zou, B. L. Li, H. Q. Luo, and N. B. Li, "0D-2D heterostructures of $\mathrm{Au}$ nanoparticles and layered $\mathrm{MoS}_{2}$ for simultaneous detections of dopamine, ascorbic acid, uric acid, and nitrite," Sensors and Actuators B: Chemical, vol. 253, pp. 352-360, 2017.

[48] J. Yan, S. Liu, Z. Zhang et al., "Simultaneous electrochemical detection of ascorbic acid, dopamine and uric acid based on graphene anchored with Pd-Pt nanoparticles," Colloids and Surfaces B: Biointerfaces, vol. 111, pp. 392-397, 2013.

[49] F. C. Vicentini, P. A. Raymundo-Pereira, B. C. Janegitz, S. A. S. Machado, and O. Fatibello-Filho, "Nanostructured carbon black for simultaneous sensing in biological fluids," Sensors and Actuators B: Chemical, vol. 227, pp. 610-618, 2016.

[50] H. Yang, J. Zhao, M. Qiu et al., "Hierarchical bi-continuous Pt decorated nanoporous Au-Sn alloy on carbon fiber paper for ascorbic acid, dopamine and uric acid simultaneous sensing," Biosensors and Bioelectronics, vol. 124-125, pp. 191-198, 2019. 